\title{
A STUDY ON PREVALENCE OF DIABETES AND PRE-DIABETES IN A NEWLY DIAGNOSED TUBERCULOSIS PATIENTS
}

\author{
Ravishankar Natarajaboopathy1, Nalini Jayanthi $N^{2}$
}

${ }^{1}$ Assistant Professor, Department of Medicine, Chengalpattu Medical College.

${ }^{2}$ Associate Professor, Department of Thoracic Medicine, Chengalpattu Medical College.

ABSTRACT
BACKGROUND
India is a country with high prevalence of both Diabetes Mellitus and Tuberculosis. In view of the increased prevalence of Diabetes
among tuberculosis patients, Diabetes is considered as a risk factor for TB. In addition to this Diabetes influences, the presentation
and treatment outcome of Tuberculosis patient. A good control of Diabetes is essential for a better treatment outcome in TB patients.
The aim of this study is to study the prevalence of Diabetes and Pre-Diabetes among newly diagnosed TB patients and to study
the impact of Diabetes on tuberculosis presentation among the same group of patients.

\section{MATERIALS AND METHODS}

132 patients who were diagnosed as TB positive were screened for Diabetes by history of Diabetes, FBS, OGTT and by HbA1C, based on which they were classified into 3 groups namely Non-Diabetic (Non-DMTB), Pre-Diabetic (Pre-DMTB) and Diabetic (DMTB). The prevalence of DM and Pre-DM were calculated. Parameters like Age, Sex, family history of DM, presentation as Pulmonary TB, High Sputum Positivity (3+) and Radiological presentation are compared among the 3 groups.

\section{RESULTS}

The prevalence of diabetes and pre-diabetes among TB patients were $38.6 \%$ and $18.9 \%$ respectively. The male:female ratio is significantly high in diabetic and pre-diabetic TB patients when compared with non-diabetic TB patients (80.4:19.6, 88:12 vs. 51.8:48.2). The mean age is significantly high in both DMTB and Pre-DMTB patients (52.92, 45.4 vs. 35.33). Family history of DM is significantly high among DMTB patients. DMTB patients presents predominantly with pulmonary tuberculosis and high sputum positivity (3+). The radiological presentation in DM TB patients are as increased presentation of bilateral disease and cavity formation.

\section{CONCLUSION}

There is a high prevalence of DM and pre-DM among newly diagnosed TB patients. Male sex, increasing age and family history of DM are risk factors. The radiological presentation also differ in tuberculosis patients with diabetes.

\section{KEYWORDS}

Diabetes Mellitus, Pre-Diabetes, Pulmonary Tuberculosis, Sputum Positivity.

HOW TO CITE THIS ARTICLE: Natarajaboopathy R, Jayanthi NN. A study on prevalence of diabetes and pre-diabetes in a newly diagnosed tuberculosis patients. J. Evolution Med. Dent. Sci. 2016;5(99):7231-7233, DOI: 10.14260/Jemds/2016/1636

\begin{abstract}
BACKGROUND
People with a weak immune system as a result of chronic diseases such as diabetes are at a higher risk of progressing from latent to active TB. People with diabetes have a higher risk of TB compared to people without diabetes. Early detection can help improve care and control of both diabetes and tuberculosis. WHO and International Union against TB and Lung disease recommends all people with TB should be screened for diabetes and Screening for TB in people with diabetes should be considered, particularly in settings with high TB prevalence. People with diabetes who are diagnosed with TB have a higher risk of death during TB treatment and of TB relapse after treatment. WHO recommended treatments should be rigorously implemented for people with
\end{abstract}

Financial or Other, Competing Interest: None.

Submission 05-11-2016, Peer Review 29-11-2016,

Acceptance 05-12-2016, Published 12-12-2016.

Corresponding Author:

Ravishankar Natarajaboopathy,

Assistant Professor,

Department of General Medicine,

Chengalpattu Medical College.

E-mail: doctormarchman@rediffmail.com

DOI: $10.14260 /$ jemds $/ 2016 / 1636$
TB/diabetes. Diabetes is complicated by the presence of infectious diseases including TB. It is important that proper care for diabetes is provided to those that are suffering from TB/diabetes. This study aims at screening for the prevalence of DM among newly diagnosed TB patients.

\section{MATERIALS AND METHODS}

The patients of age group between 15 and 85 years who are diagnosed to have Tuberculosis in The Department of Thoracic Medicine, Chengalpattu Medical College, during the period from October 2013 to September 2014 were included in the study. Patients who were already known cases of $\mathrm{TB}$, defaulters, failures and relapses after ATT are not included in the study. Patients who are terminally ill, HIV positive patients and patients who are not willing to give consent are not included in the study.

After obtaining the informed consent from the patients they were asked for history of Diabetes Mellitus, family history of DM among family members (father, mother and siblings). Their glycaemic status was tested using their FBS and an OGTT using 75 gm glucose. Their HbA1C was also tested by HPLC method. 
The following were considered as Diabetic Patients

1. Patients who are already diagnosed as DM who are on treatment for it.

2. $\mathrm{FBS}>125 \mathrm{mg} \%$.

3. 2 hrs. post glucose plasma glucose $>199 \mathrm{mg} \%$.

4. $\mathrm{HbA} 1 \mathrm{C}>6.4 \%$.

The Diagnosis of Pre-Diabetes was Made on the following Criteria

1. FBS $\geq 100 \mathrm{mg} \%$ and $<126 \mathrm{mg} \%$ - IFG.

2. $2 \mathrm{hrs}$. post glucose plasma glucose $>140 \mathrm{mg} \%$ and $<200$ $\mathrm{mg} \%$.

3. $\mathrm{HbA} 1 \mathrm{C}>5.8 \%$ to $6.4 \%$.

The TB patients are classified as diabetic, pre-diabetic and non-diabetic groups and the parameters are compared. The mean value of each parameter among the diabetic and prediabetic groups are compared with that of non-diabetic group using Chi square test and tested for statistical significance.

\section{RESULTS}

Of the total 132 eligible patients who were included in the study, 51 were diabetic, 25 were pre-diabetic and 56 were non-diabetic.

\begin{tabular}{|c|c|c|c|c|}
\hline & Total & Diabetic & $\begin{array}{c}\text { Pre- } \\
\text { Diabetic }\end{array}$ & $\begin{array}{c}\text { Non- } \\
\text { Diabetic }\end{array}$ \\
\hline $\begin{array}{c}\text { Number of } \\
\text { Patients }\end{array}$ & 132 & 51 & 25 & 56 \\
\hline Male & 92 & 41 & 22 & 29 \\
\hline Female & 40 & 10 & 3 & 27 \\
\hline Age range (yrs.) & $14-$ & $25-70$ & $19-71$ & $14-65$ \\
\hline Pulmonary TB & 96 & 41 & 20 & 35 \\
\hline Sputum 3+ & 18 & 13 & 2 & 3 \\
\hline Sputum 2+ & 24 & 9 & 5 & 10 \\
\hline Sputum 1+ & 30 & 13 & 11 & 6 \\
\hline Sputum Scanty & 09 & 3 & 1 & 5 \\
\hline Sputum Negative & 15 & 3 & 1 & 11 \\
\hline Extra Pulmonary & 36 & 10 & 5 & 21 \\
\hline Pleural Effusion & 23 & 5 & 3 & 15 \\
\hline Right Sided & 19 & 5 & 3 & 11 \\
\hline Left Sided & 04 & 0 & 0 & 4 \\
\hline Abdominal TB & 04 & 3 & 1 & 0 \\
\hline Mastitis & 01 & 1 & 0 & 0 \\
\hline Skeletal TB & 01 & 0 & 1 & 0 \\
\hline Lymphadenopathy & 07 & 1 & 0 & 6 \\
\hline & Table 1. Patient Profile & \\
\hline
\end{tabular}

\begin{tabular}{|c|c|c|c|}
\hline & Diabetic & $\begin{array}{c}\text { Non- } \\
\text { Diabetic }\end{array}$ & $\begin{array}{c}\text { P } \\
\text { Value }\end{array}$ \\
\hline Male : Female & $80.4: 19.6$ & $51.8: 48.2$ & 0.0018 \\
\hline Mean Age & $52.92 \pm 10.7$ & $35.33 \pm 14.29$ & 0.0001 \\
\hline $\begin{array}{c}\text { Positive Family } \\
\text { H/O }\end{array}$ & $54.9 \%$ & $1.8 \%$ & 0 \\
\hline Pulmonary TB & $80.4 \%$ & $62.5 \%$ & 0.0415 \\
\hline $\begin{array}{c}\text { High Positive } \\
\text { Sputum }\end{array}$ & $30.9 \%$ & $8.8 \%$ & 0.018 \\
\hline $\begin{array}{c}\text { Bilateral } \\
\text { Involvement }\end{array}$ & $29 / 51$ & $15 / 56$ & 0.0015 \\
\hline $\begin{array}{c}\text { Lower zone } \\
\text { involvement }\end{array}$ & $6 / 51$ & $6 / 56$ & 0.86 \\
\hline Cavity formation & $9 / 51$ & $3 / 56$ & 0.044 \\
\hline Military mottling & $5 / 51$ & $1 / 56$ & 0.071 \\
\hline \multicolumn{2}{|c|}{ Table 2. Diabetic Vs. Non-Diabetic TB Patients } \\
\hline \multicolumn{4}{|c|}{}
\end{tabular}

\begin{tabular}{|c|c|c|c|}
\hline & $\begin{array}{c}\text { Pre- } \\
\text { Diabetic }\end{array}$ & $\begin{array}{c}\text { Non- } \\
\text { Diabetic }\end{array}$ & $\begin{array}{c}\text { P } \\
\text { Value }\end{array}$ \\
\hline Male : Female & $88: 12$ & $51.8: 48.2$ & 0.0018 \\
\hline Mean age & $45.4 \pm 16.8$ & $35.33 \pm 14.29$ & 0.0069 \\
\hline Positive family H/0 & $12 \%$ & $1.8 \%$ & 0.63 \\
\hline Pulmonary TB & $80 \%$ & $62.5 \%$ & 0.12 \\
\hline $\begin{array}{c}\text { High positive } \\
\text { sputum }\end{array}$ & $13.3 \%$ & $8.8 \%$ & 0.063 \\
\hline $\begin{array}{c}\text { Bilateral } \\
\text { involvement }\end{array}$ & $13 / 25$ & $15 / 56$ & 0.02 \\
\hline $\begin{array}{c}\text { Lower zone } \\
\text { involvement }\end{array}$ & $2 / 25$ & $6 / 56$ & 0.7052 \\
\hline Cavity formation & $5 / 25$ & $3 / 56$ & 0.4130 \\
\hline Military mottling & $1 / 25$ & $1 / 56$ & 0.55 \\
\hline \multicolumn{2}{|c|}{ Table 3. Pre-Diabetes Vs. Non-Diabetes } \\
\hline \multicolumn{4}{|l}{}
\end{tabular}

\section{DISCUSSION}

\section{Prevalence}

\section{Diabetes Mellitus (DM)}

The prevalence of DM among the newly diagnosed TB patients in our study was $38.6 \%$. Of this, $25.75 \%$ were previously known cases of DM and about $12.75 \%$ of patients were newly diagnosed DM. This prevalence is very high when compared with the $13 \%$ of the nationwide pilot project. ${ }^{1}$ The prevalence of DM among TB patients in various other studies conducted in various other parts of India are -

\begin{tabular}{|c|c|}
\hline Studies & Prevalence \\
\hline Viswanathan et al $^{2}$ & $25.3 \%$ \\
\hline Balakrishnan et al $^{3}$ & $44 \%$ \\
\hline Nair et al $^{4}$ & $32.4 \%$ \\
\hline Mansuri et al & $15.3 \%$ \\
\hline Sounderajan et al & \\
\hline
\end{tabular}

\section{Pre-Diabetes (Pre-DM)}

The prevalence of Pre-DM among the newly diagnosed TB patients in our study was $18.9 \%$. Of this $1.5 \%$ were IFG, $3.8 \%$ were IGT and $13.6 \%$ were both IFG and IGT. The prevalence of Pre-DM among the TB patients in the study by Viswanathan et $\mathrm{al}^{2}$ in the same geographical area was $24.5 \%$.

\section{Sex}

The male-to-female ratio in the DMTB patients was 80.4:19.6. This was significantly high $(\mathrm{P}=0.0018)$ when compared with the Non-DM TB patients ratio of 51.8:48.2.

The ratio in pre-DM TB patients 88:12 was also significantly high $(\mathrm{P}=0.0018)$ when compared with the nondiabetic TB patients.

The prevalence among the males was significantly higher (44.56\%) when compared with that of the females (25\%). This is similar to the studies conducted by Viswanathan et $\mathrm{al}^{2}$ and Balakrishnan et al. ${ }^{3}$

\section{Age}

The mean age of the DM TB patients in our study was 52.92 years and the mean age of the pre-DM TB patients was 45.4 yrs. Both are significantly high $(P=0.0001$ and 0.0069 respectively) when compared with that of the non-DM TB patients.

The mean age of DMTB patients in study by Viswanathan et $\mathrm{al}^{2}$ was 49.3 yrs. and by Mansuri et al ${ }^{5}$ was $46.8 \mathrm{yrs}$. In both the studies, the age of DMTB patients was significantly high when compared with that of Non-DMTB patients. 
Age $>50$ yrs. is a risk factor for DM among TB patients in Balakrishnan et $\mathrm{al}^{3}$ and Nair et al. ${ }^{4}$ In our study about $76.47 \%$ of DMTB patients were of age $>50 \mathrm{yrs}$.

\section{Family History of DM}

The history of DM among one or more family members (father, mother or siblings) is significantly high among the DMTB patients ( $54.9 \% ; \mathrm{p}=0$ ) in the studies by Viswanathan et $\mathrm{al}^{2}$ and Sounderajan et $\mathrm{al}^{6}$ have confirmed that family history as a risk factor for DM among TB patients. The family history of DM is not significantly high among pre-DMTB patients $(\mathrm{P}=0.63)$.

\section{Pulmonary Vs. Extrapulmonary TB Patients}

There is an increased presentation of pulmonary TB among the DMTB patients when compared with non-DMTB patients (80.4\% Vs. $62.5 \%$; $P=0.0415$ ). There is no such statistically significant increased presentation of pulmonary TB in the PreDMTB group of patients $(\mathrm{P}=0.12)$.

\section{High Positive Sputum}

The pulmonary TB patients were classified as,

1. High Sputum positivity - Sputum $3+$.

2. Low sputum positivity - Sputum $2+, 1+$ Scanty, negative.

The DMTB patients have significantly high $(\mathrm{p}=0.018)$ presentation of high sputum positivity (30.9\%) when compared with the Non-DMTB patients. There is no such significant $(\mathrm{P}=0.63)$ high sputum positivity among the preDMTB patients. The study by Singla et al 7 have also shown an increased presentation of (65.2\%) high sputum positivity among the DMTB patients.

\section{Radiological Presentation}

The DMTB patients and Pre-DMTB patients have a significantly high bilateral lung involvement when compared with non-DMTB patients ( $\mathrm{P}=0.0015,0.02$ respectively). The DMTB patients have more tendency to form cavity when compared with non-DMTB patients. The 3 groups does not show any difference on lower zone involvement. Military mottling though more common among the DMTB and PreDMTB patients does not attain statistical significance.

Study by Tartar et al $^{8}$ also showed an increased tendency of DMTB patients to form cavity. Study by Qazi M. A., Sharif N., Warraich M. M. et $\mathrm{al}^{9}$ also showed increased cavity formation, bilateral involvement and atypical location. These findings were consistent with those of Zuber et al.10 These findings were similar to Shaikh et al,11 while Saulat et al $^{12}$ and Bacakoglu et al ${ }^{13}$ found higher number of patients affected with cavitatory lung involvement.

\section{CONCLUSION}

The prevalence of diabetes and pre-diabetes among the newly diagnosed DM patients are $38.6 \%$ and $18.9 \%$ respectively.
Male sex and age are risk factors for diabetes among TB patients. Family history of diabetes is also a risk factor for diabetes. Diabetic TB patients have significantly high pulmonary involvement, bacillary load, bilateral involvement and cavity formation. Lower zone involvement and cavity military mottling does not show any significant difference.

\section{REFERENCES}

1. India Tuberculosis-Diabetes Study Group. Screening of patients with tuberculosis for diabetes mellitus in India. Tropical Medicine and International Health 2013;18(5):636-45.

2. Viswanathan V, Kumpatla S, Aravindalochanan V, et al. Prevalence of diabetes and pre-diabetes and associated risk factors among tuberculosis patients in India. PLoS ONE 2012;7(7):e41367.

3. Balakrishnan S, Vijayan S, Nair S, et al. High diabetes prevalence among tuberculosis cases in Kerala, India. PLoS ONE 2012;7(10):e46502.

4. Nair S, Kumari AK, Subramonianpillai J, et al. High prevalence of undiagnosed diabetes among tuberculosis patients in peripheral health facilities in Kerala. PHA 2013;3(Suppl 1):S38-S42.

5. Mansuri S, Chaudhari A, Singh A, et al. Prevalence of diabetes among tuberculosis patients at urban health centre, Ahmedabad. International Journal of Scientific Study 2015;3(4):115-8.

6. Raghuraman $\mathrm{S}$, Vasudevan $\mathrm{KP}$, Govindarajan $\mathrm{S}$, et al. Prevalence of diabetes mellitus among tuberculosis patients in urban Puducherry. $\mathrm{N}$ Am J Med Sci 2014;6(1):30-4.

7. Singla R, Khan N, Al-Sharif N, et al. Influence of diabetes on manifestations and treatment outcome of pulmonary TB patients. Int J Tuberc Lung Dis 2006;10(1):74-9.

8. Tatar D, Senol G, Alptekin S, et al. Tuberculosis in diabetics: features in an endemic area. Jpn J Infect Dis 2009;62(6):423-7.

9. Qazi MA, Sharif N, Warraich MM, et al. Radiological pattern of pulmonary tuberculosis in diabetes mellitus. Annals 2009;15(2):71-4.

10. Ahmad Z, Zaheer MS. Lower lung field tuberculosis-a clinical study. JIACM 2003;4(2):116-20.

11. Shaikh MA, Singla R, Khan NB, et al. Does diabetes alter the radiological presentation of pulmonary tuberculosis. Saudi Med J 2003;24(3):278-81.

12. Khan SU, Cheema TM, Tariq $M$, et al. Pulmonary tuberculosis in diabetics versus non-diabetics. Pakistan Postgraduate Medical Journal 1997;8(3-4).

13. Bacakoglu F, Basoglu OK, Cok G, et al. Pulmonary tuberculosis in patients with diabetes mellitus. Respiration 2001;68(6):595-600. 